
)

\title{
CLIMA Y URBANIZACIÓN
}

Prof. Claudia Verónica GÓMEZ Prof. María Emilia PÉREZ

ELABORADO A PARTIR DE LA COMPILACIÓN DE BIBLIOGRAFÍA CONSULTADA Y DE INTERNET

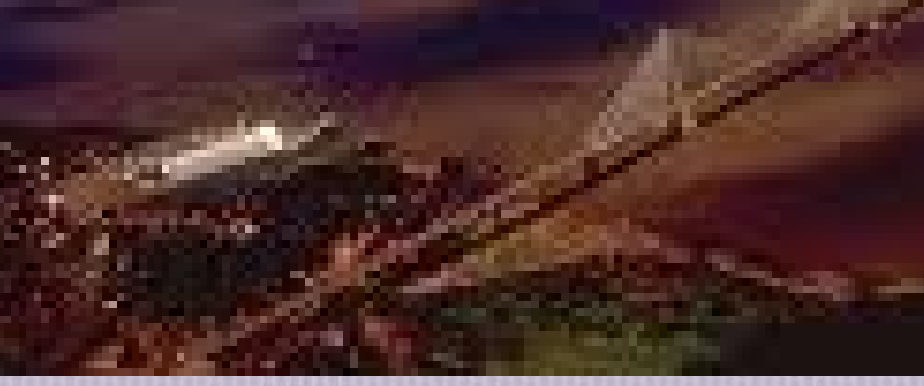

Departamento de Geografía Facultad de Humanidades Universidad Nacional del Nordeste 
Revista Geográfica Digital. IGUNNE. Facultad de Humanidades. UNNE. Año 9. № 18. Julio - Diciembre 2012. ISSN 1668-5180 Resistencia, 18

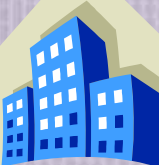

Mucho antes de que empezara a tomar forma la ciencia (Climatología) tal como hoy la conocemos, los hombres observaron el cielo, notaron las características de las estaciones y procuraron ORGANIZAR SUS ACTIVIDADES en función del tiempo cambiante", Petterssen (1976).

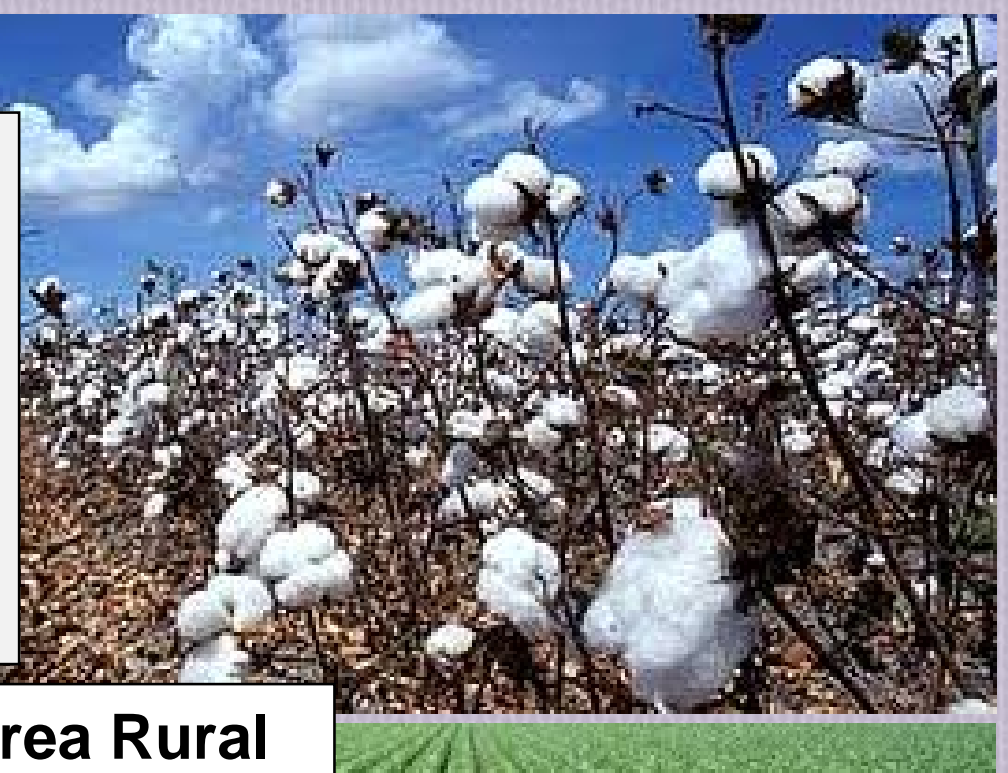

\section{Actividades en el Área Rural}
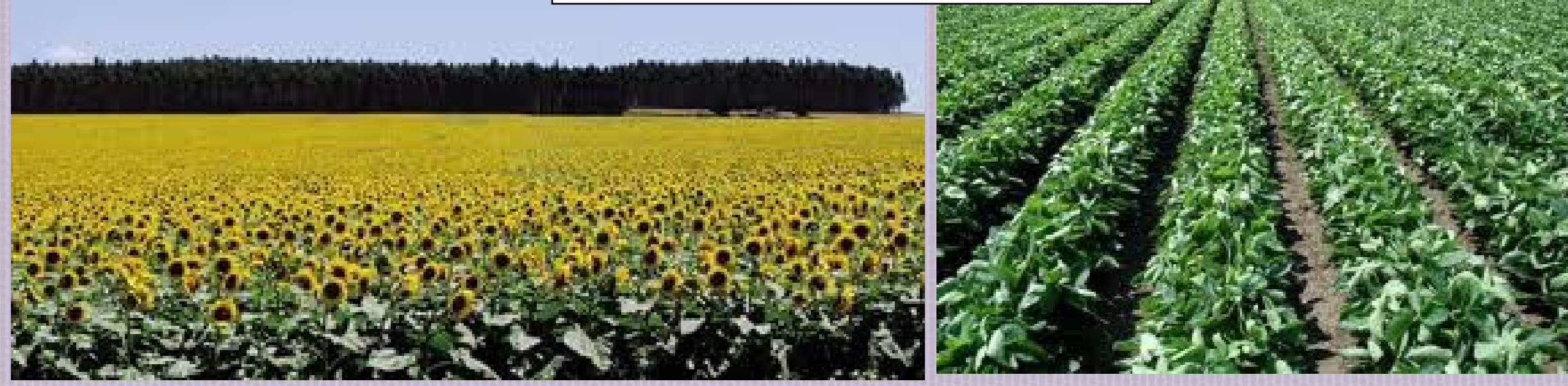

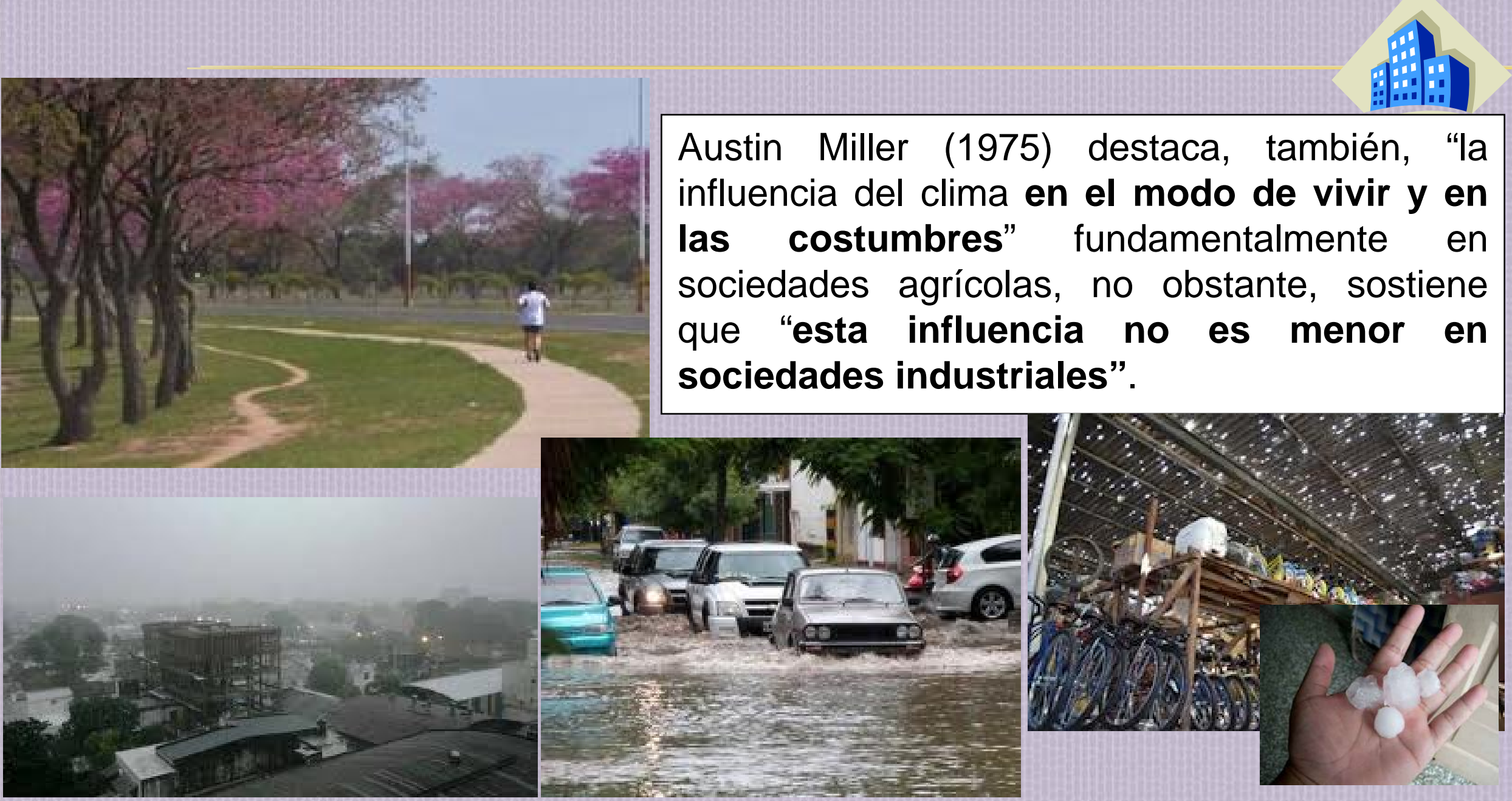

"En definitiva el clima está presente e influye positiva o negativamente en muchos aspectos de nuestras vidas". 


\section{LA CLIMATOLOGÍA COMO CIENCIA Y LAS TENDENCIAS ACTUALES}

- Primeros observatorios meteorológicos y conocimientos sistemáticos del Clima como disciplina.

Siglo XIX

- Defendida por Hann, quien caracteriza al Clima a partir de los valores medios de los elementos, principalmente temperatura y precipitación, registrados en los observatorios. gía

Analítica

- Pedelaborde rechaza la concepción analítica de la Climatología. Se apoya en la definición de Max Sorre y modifica el objeto de estudio de esta disciplina. En definitiva se estudia la sucesión habitual de los distintos estados de la atmósfera (tipos de tiempo). gía Dinámica

El Clima como Sistema y
- Dos hechos importantes convergen, a partir de la década del ' 70 , en esta nueva tendencia: a) la preocupación por los graves problemas ambientales y, b) la consolidación de la Teoría General de Sistema. 


\section{LA CLIMATOLOGÍA COMO CIENCIA Y LAS TENDENCIAS ACTUALES}

El Clima como SISTEMA:

"Es un Factor condicionante en la configuración del paisaje".
El Clima como RECURSO:

"Es un recurso enormemente variable que influye en la sociedad".

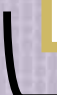

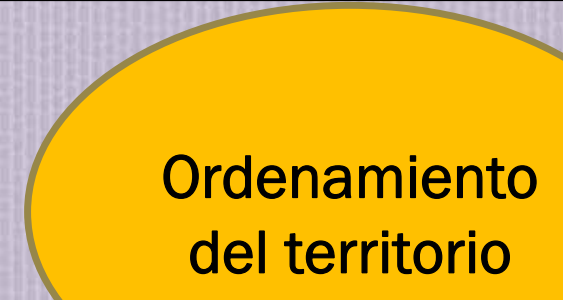

Confortabilidad Humana

"Condiciones ambientales favorables para el Hombre" 
Revista Geográfica Digital. IGUNNE. Facultad de Humanidades. UNNE. Año 9. No 18. Julio - Diciembre 2012. ISSN 1668-5180 Resistencia, Chaco

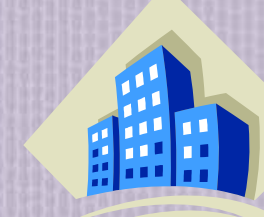

\section{CLIMA}

CONCEPTO

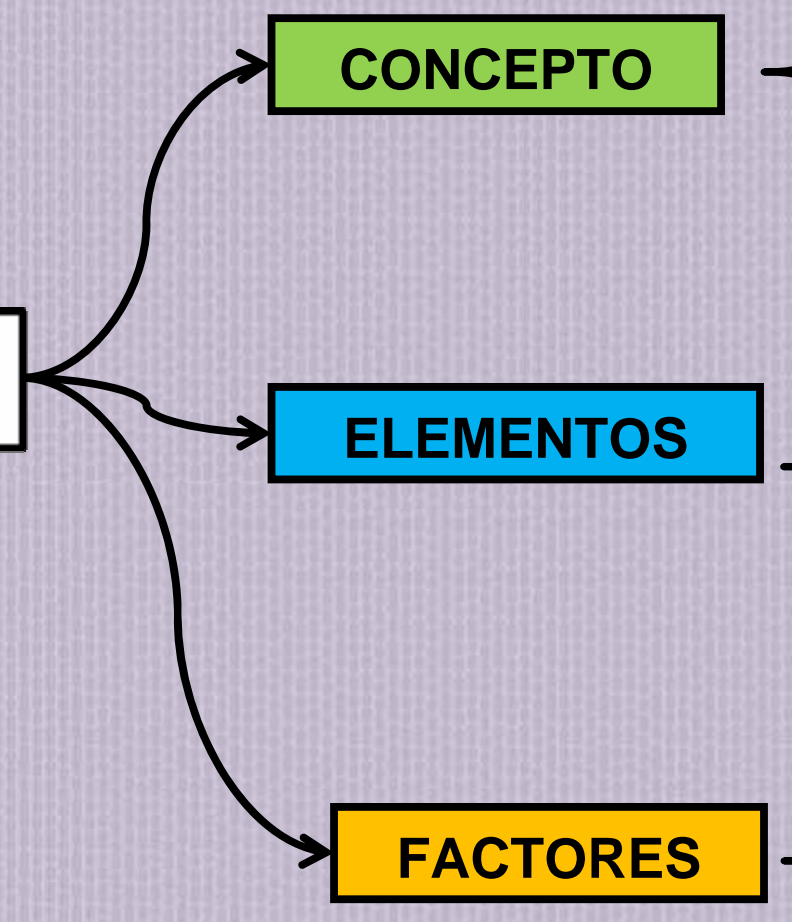

Se lo puede definir, desde una perspectiva analítica, como el estado medio de las condiciones atmosféricas, o bien, considerando su dinamismo, como la sucesión habitual de los tipos de tiempos, durante un largo período (superior a treinta años), en un lugar determinado.

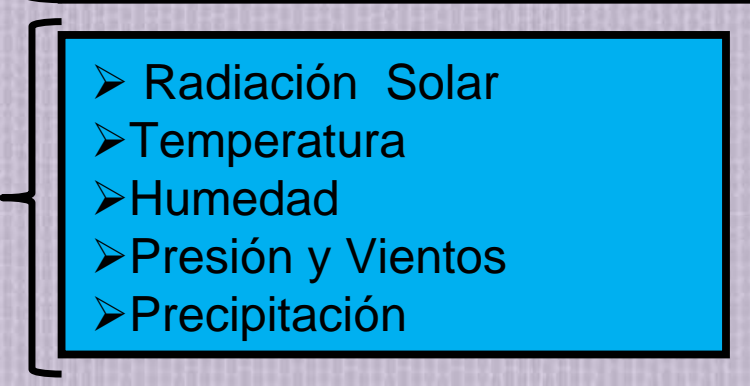

$>$ Latitud

$>$ Altitud

$>$ Relieve

$>$ Influencia marítima

$>$ Corrientes marinas 
1 Revista Geográfica Digital. IGUNNE. Facultad de Humanidades. UNNE. Año 9. No 18. Julio - Diciembre 2012. ISSN 1668-5180 Resistencia,

\section{CLIMA Y ESCALA ESPACIAL}

\section{Macroclimática o climas Zonales}

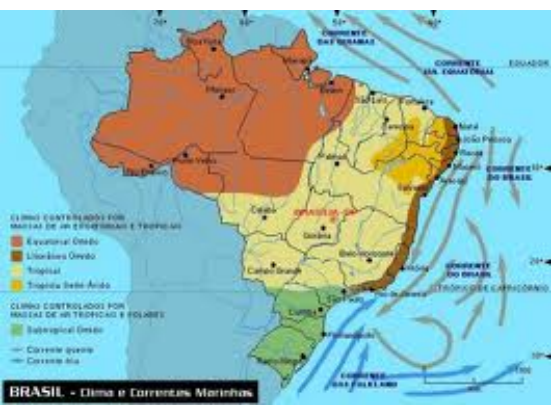

Mesoclimáticas o climas Regionales
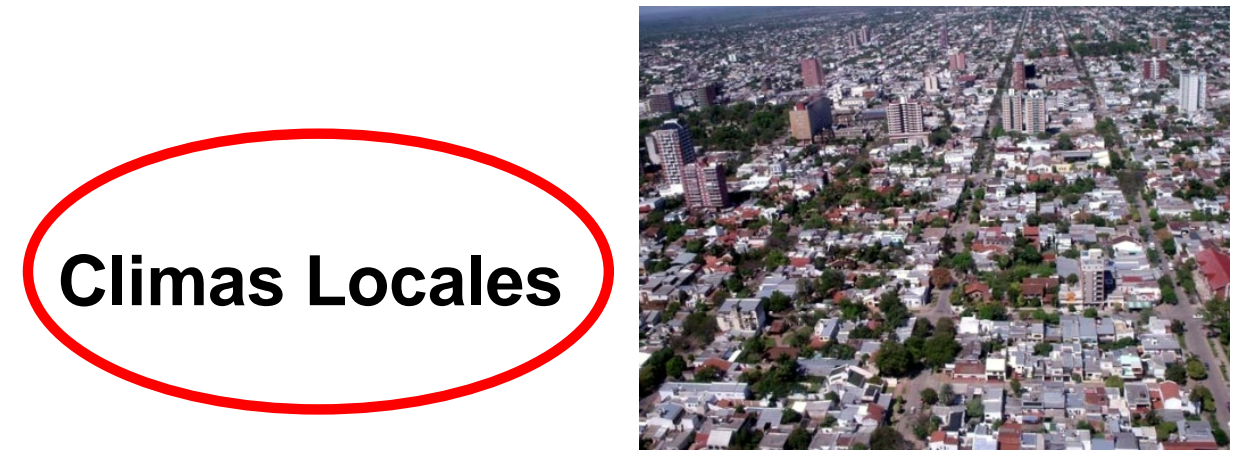

Microclimas

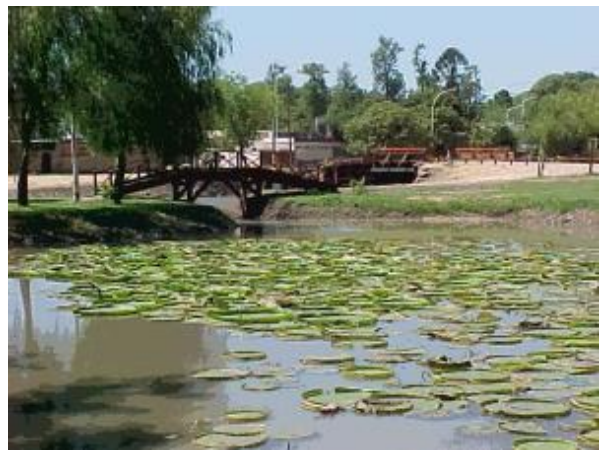

Publicado en formato digital: Prof. Claudia Verónica GÓMEZ y Prof. María Emilia PÉREZ. CLIMA Y URBANIZACIÓN . Resúmenes. Revista Geográfica Digital. IGUNNE. Facultad de Humanidades. UNNE. Año 9. № 18. Julio - Diciembre 2012. ISSN 1668-5180. Resistencia, Chaco. En: http://hum.unne.edu.ar/revistas/geoweb/default.htm 
- Revista Geográfica Digital. IGUNNE. Facultad de Humanidades. UNNE. Año 9. № 18. Julio - Diciembre 2012. ISSN 1668-5180 Resistencia, Chaco

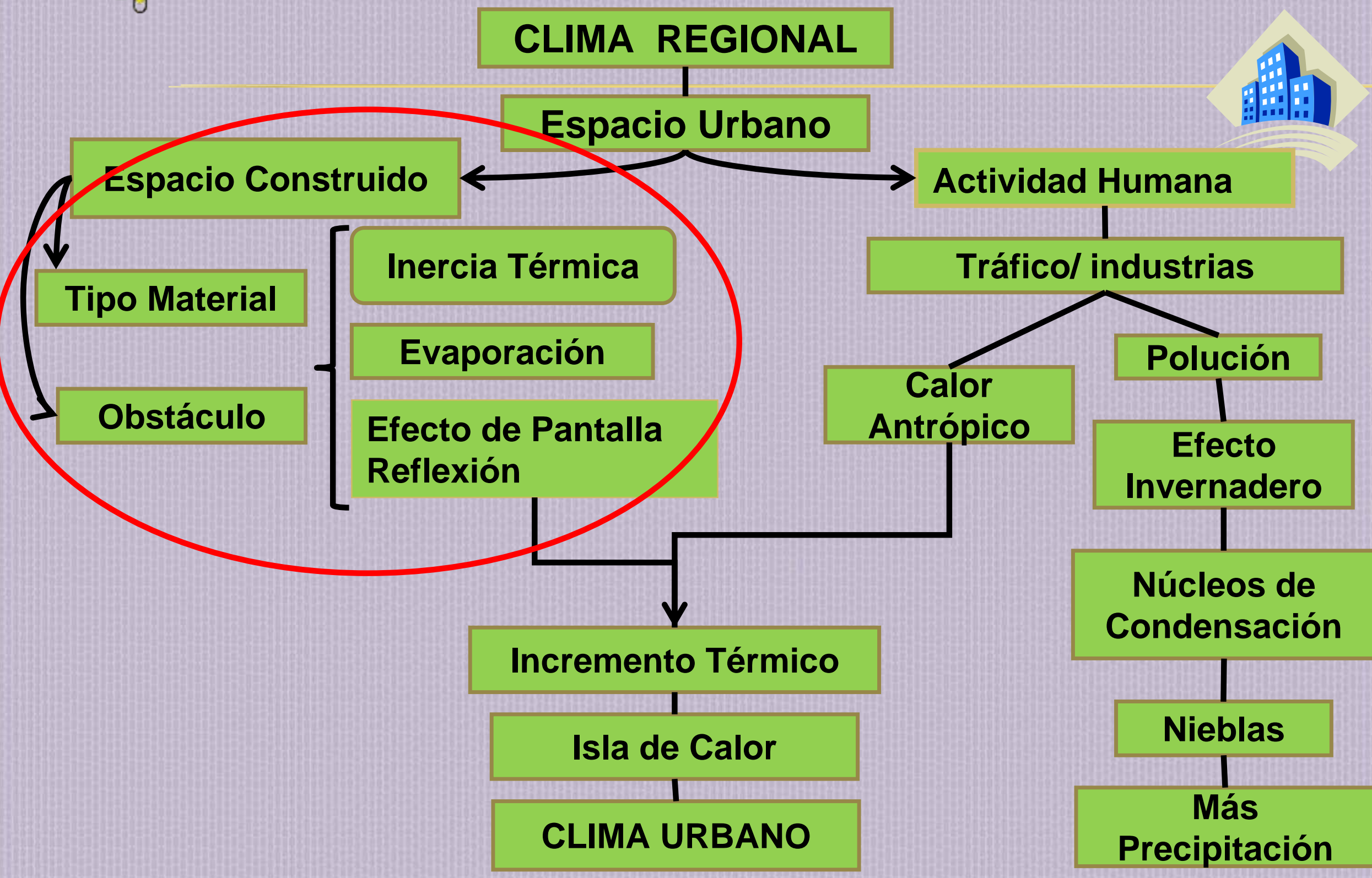


e

\section{ESPACIO CONSTRUIDO DE LA CIUDAD DE RESISTENCIA}

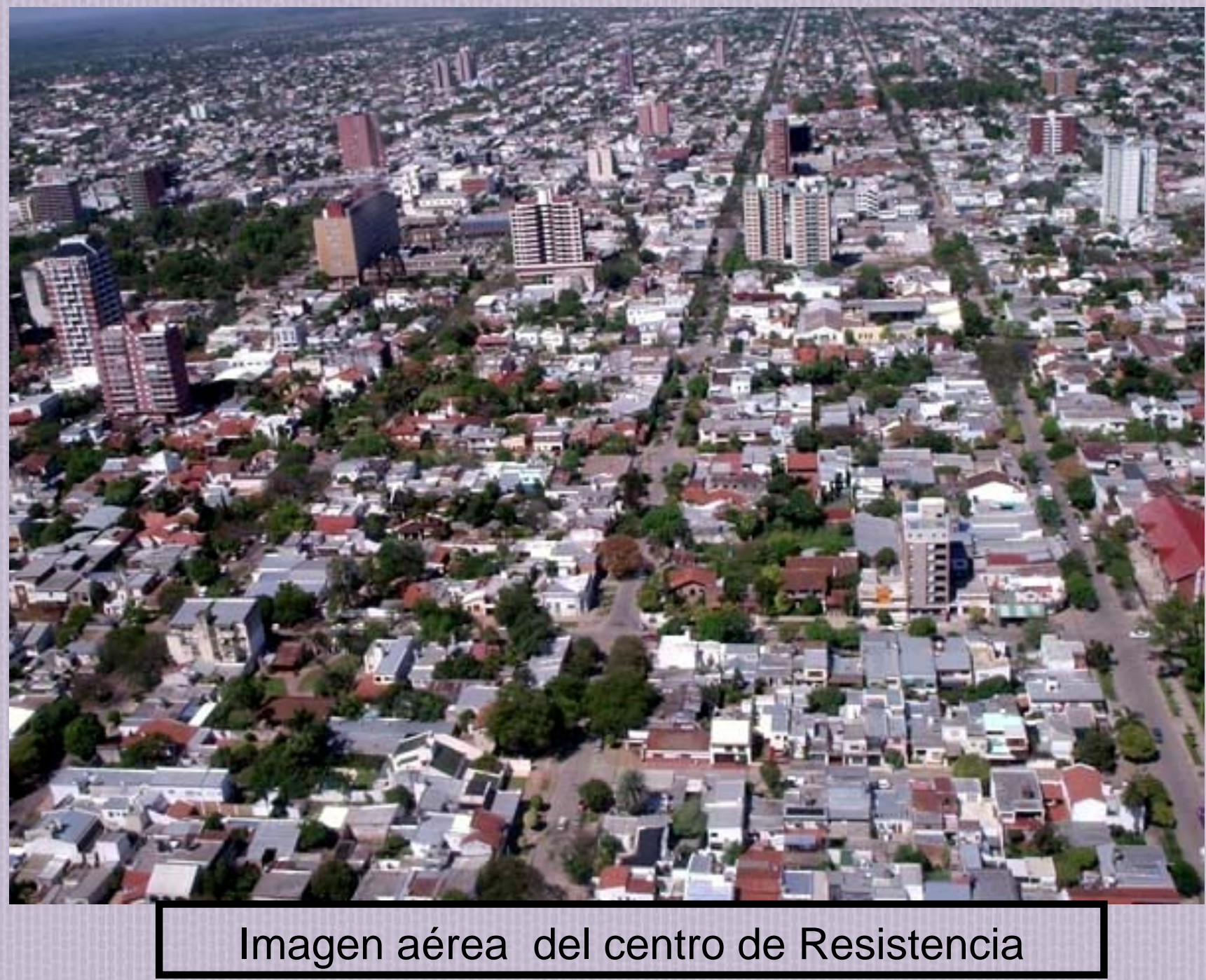

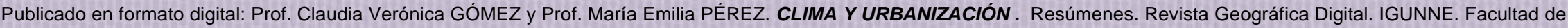
Humanidades. UNNE. Año 9. № 18. Julio - Diciembre 2012. ISSN 1668-5180 . Resistencia, Chaco. En: http://hum.unne.edu.ar/revistas/geoweb/default.htm 
Revista Geográfica Digital. IGUNNE. Facultad de Humanidades. UNNE. Año 9. No 18. Julio - Diciembre 2012. ISSN 1668-5180 Resistencia, G. Chaco

\section{ESPACIO CONSTRUIDO}

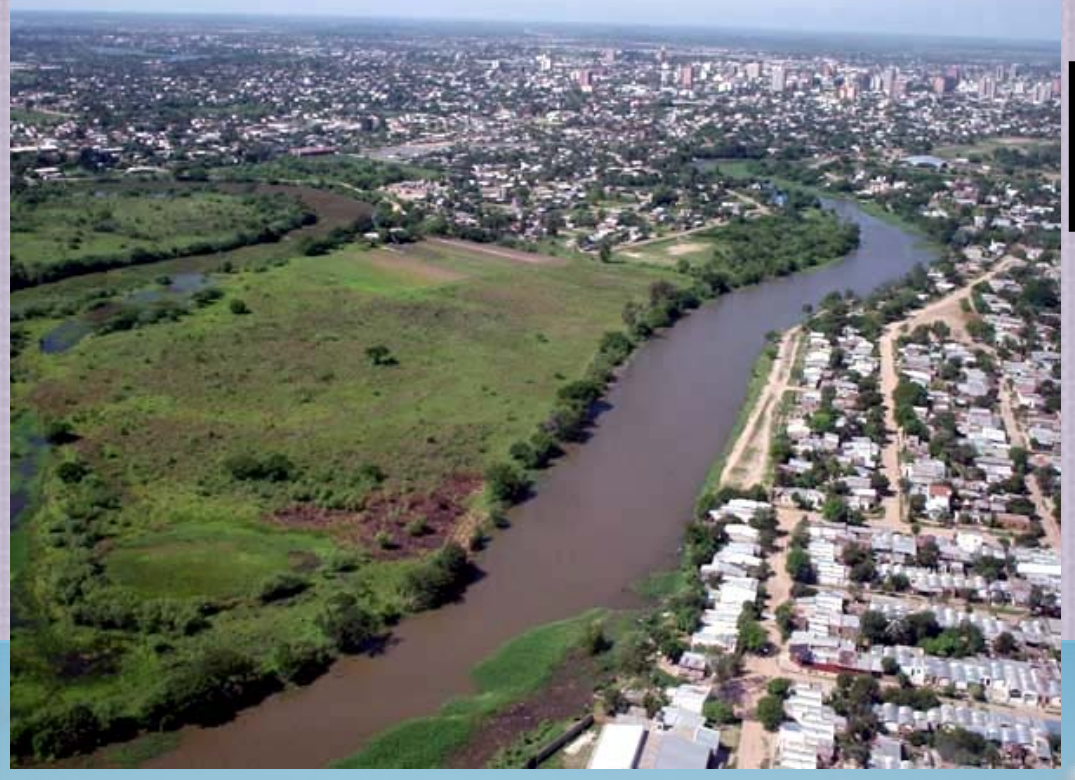

\section{Resistencia, Regatas-}

Domo del Centenario
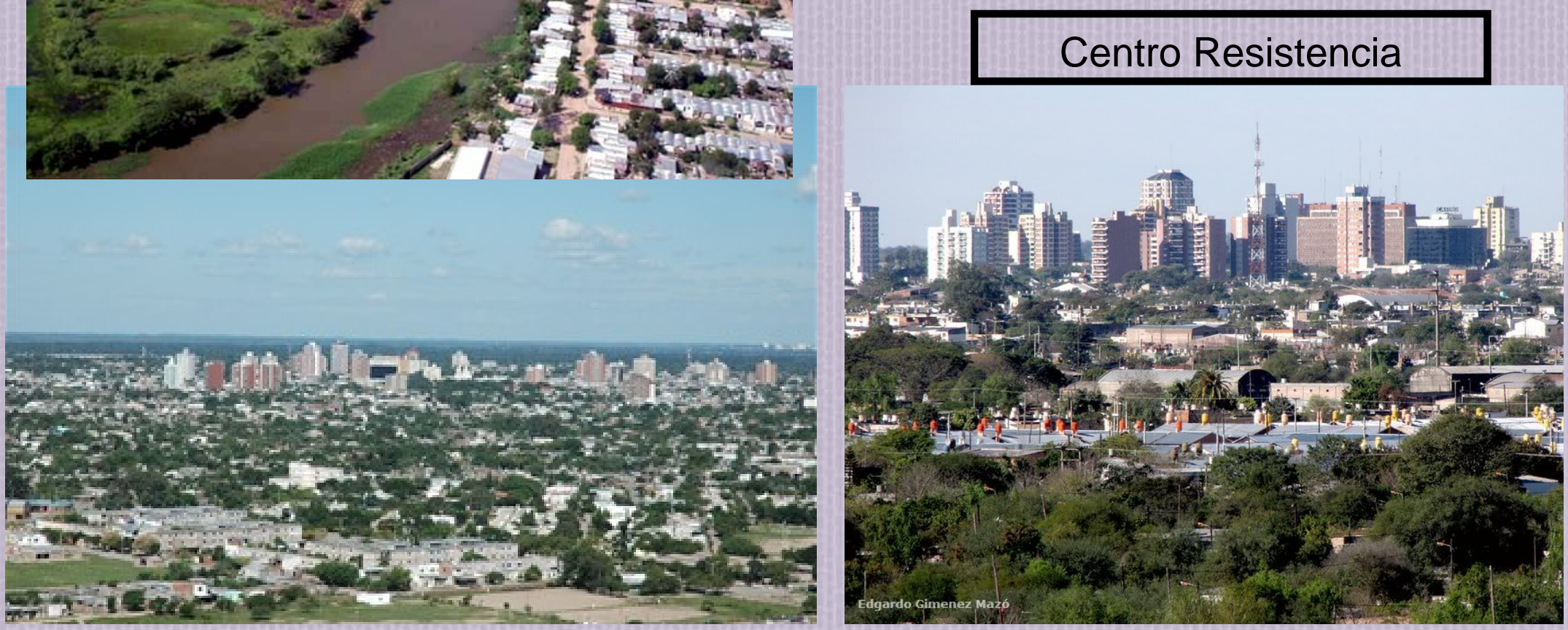

Publicado en formato digital: Prof. Claudia Verónica GÓMEZ y Prof. María Emilia PÉREZ. CLIMA Y URBANIZACIÓN . Resúmenes. Revista Geográfica Digital. IGUNNE. Facultad de Humanidades. UNNE. Año 9. № 18. Julio - Diciembre 2012. ISSN 1668-5180. Resistencia, Chaco. En: http://hum.unne.edu.ar/revistas/geoweb/default.htm 
El Clima Subtropical otorga a la región del Nordeste Argentino ciertas características en cuanto al ritmo y distribución espacial de los distintos elementos climáticos que, luego, son alterados por los factores urbanos.

\section{Variables afectadas en el área urbana de Resistencia:}

Temperatura,

Radiación solar,

Escurrimiento

Evaporación,

Presión y Vientos. 
1 Revista Geográfica Digital. IGUNNE. Facultad de Humanidades. UNNE. Año 9. No 18. Julio - Diciembre 2012. ISSN 1668-5180 Resistencia,

\section{ESPACIO CONSTRUIDO-TEMPERATURA}

Mayor capacidad calorífica de los materiales urbanos que almacenan gran cantidad de calor, poca energía consumida en la evaporación por el "rápido" escurrimiento, disminución de pérdidas de calor, desde la superficie, por irradiación nocturna (cañón urbano),
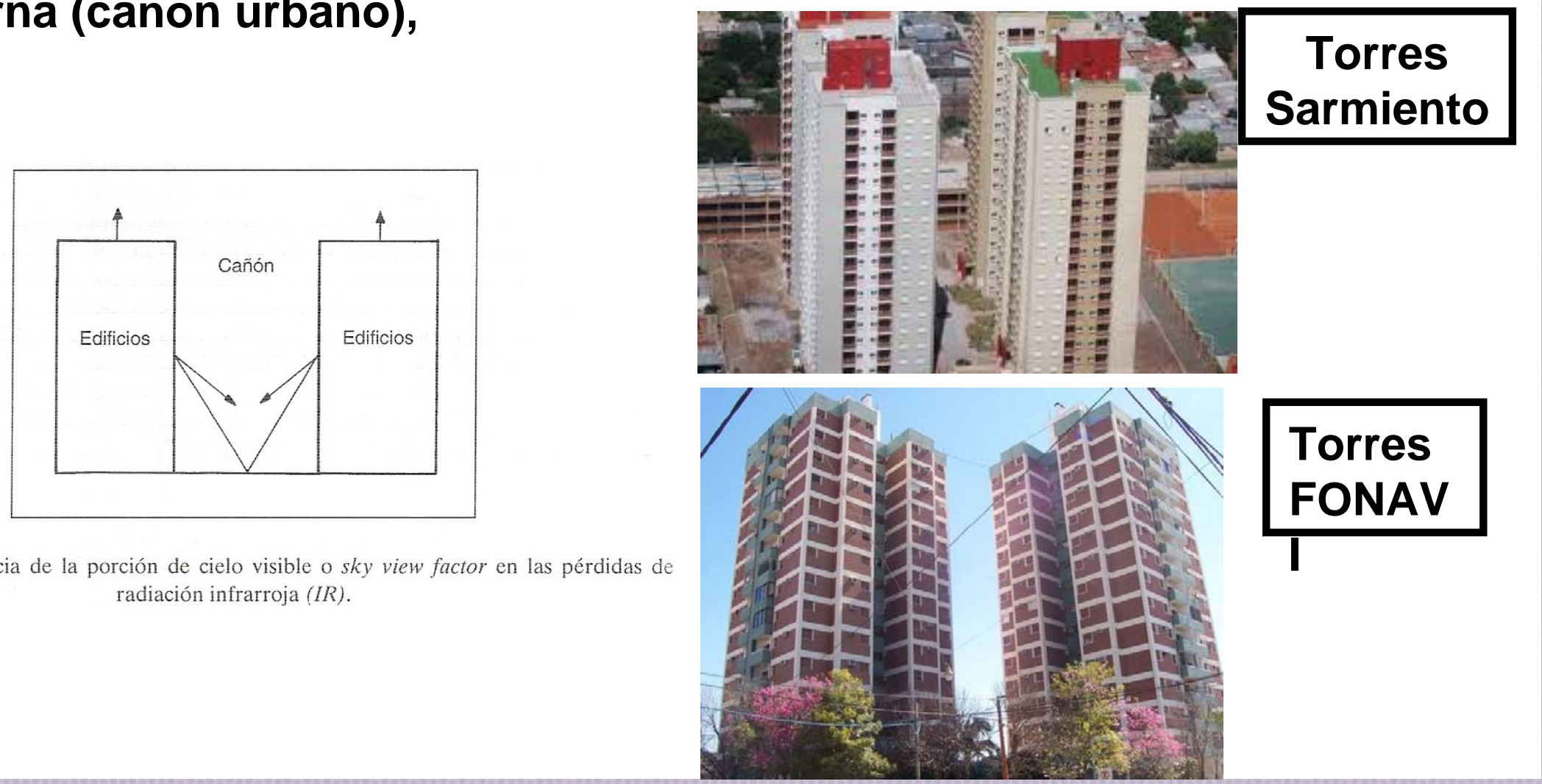

Figura 14.2. Influencia de la porción de cielo visible o sky view factor en las pérdidas de radiación infrarroja $(I R)$. 


\section{ESPACIO CONSTRUIDO-RADIACIÓN SOLAR}

Es mínima debido a la polución y sombras creadas por los edificios; $\Rightarrow$ la iluminación disminuye como consecuencia de la altura de los edificios y la estrechez de las calles,

asimismo, las formas y orientaciones de los edificios reflejan hacia numerosos planos absorbentes (techos, fachadas, etc.).
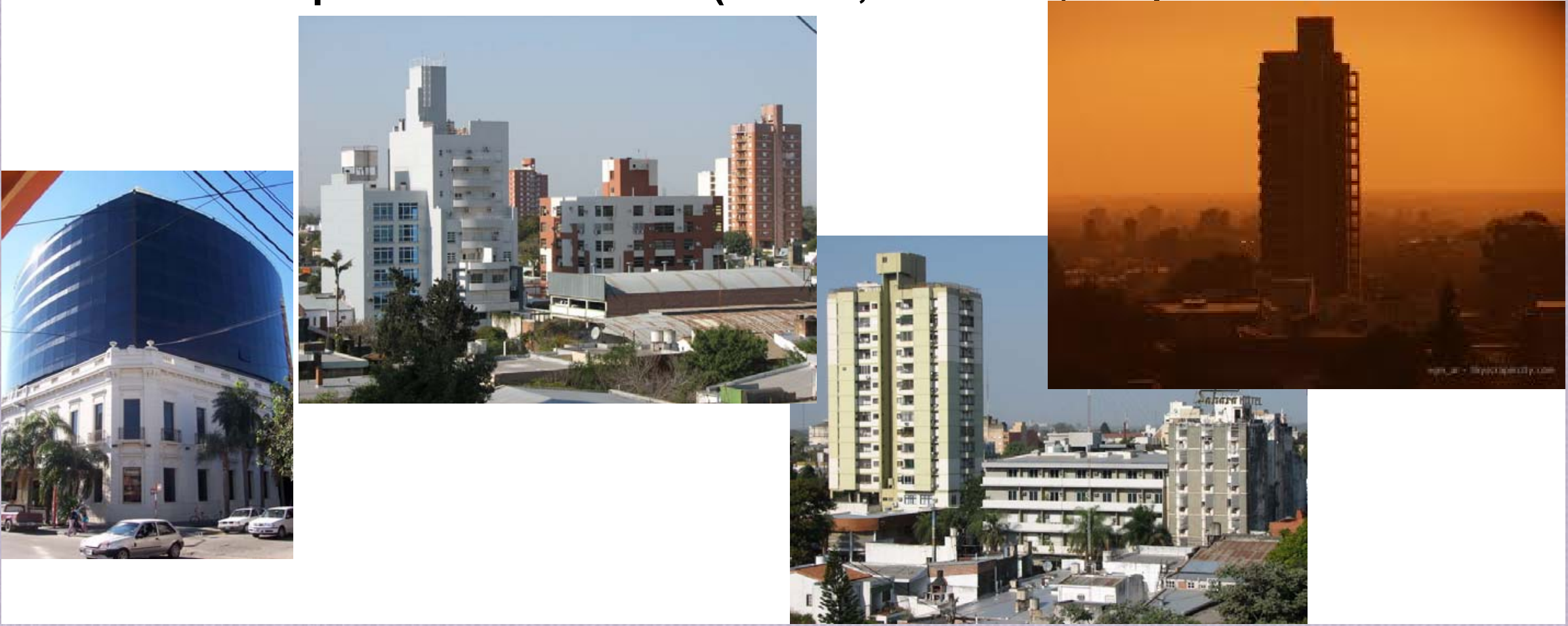


\section{ESPACIO CONSTRUIDO-ESCURRIMIENTO}

La sustitución del suelo natural por superficies de cemento (impermeables) combinados con el sistema artificial de drenaje urbano, incrementan el rápido escurrimiento superficial, no obstante, existen algunas excepciones cuando llueve más de 100 mm en pocas horas.
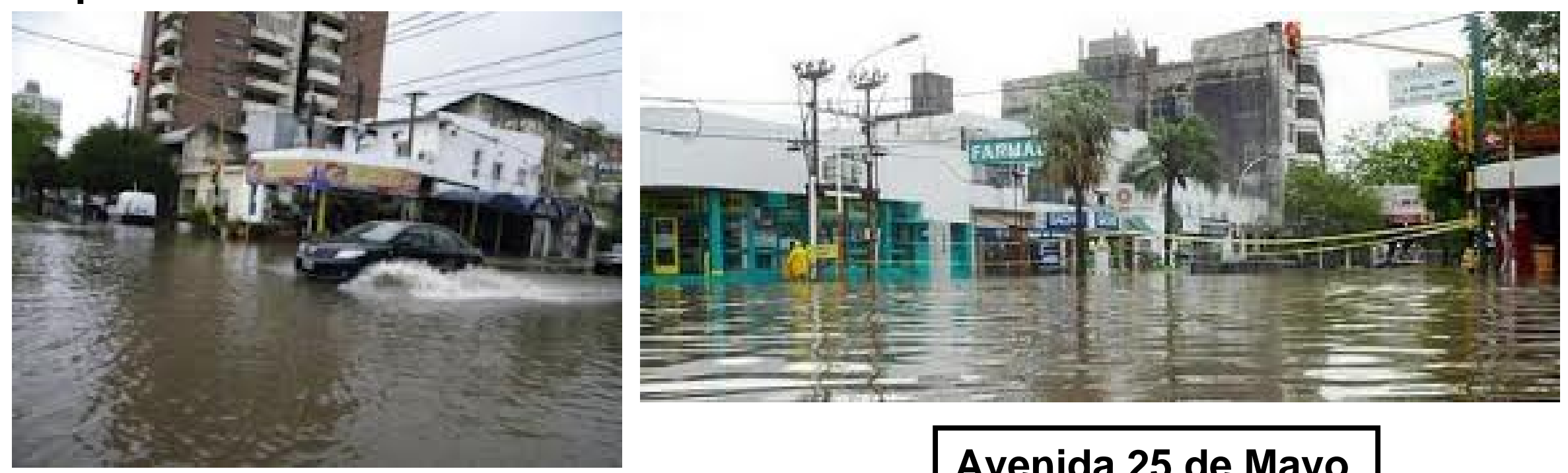

Avenida Belgrano y J. D. Perón

Avenida 25 de Mayo 


\section{ESPACIO CONSTRUIDO-EVAPORACIÓN}

El rápido escurrimiento superficial contribuye a disminuir la disponibilidad de humedad susceptible de ser evaporada,

sin embargo, se registran diferencias dentro de la misma ciudad, por ejemplo, entre un espacio construido con rápido escurrimiento y un área de esparcimiento que conserva cuerpos de agua.
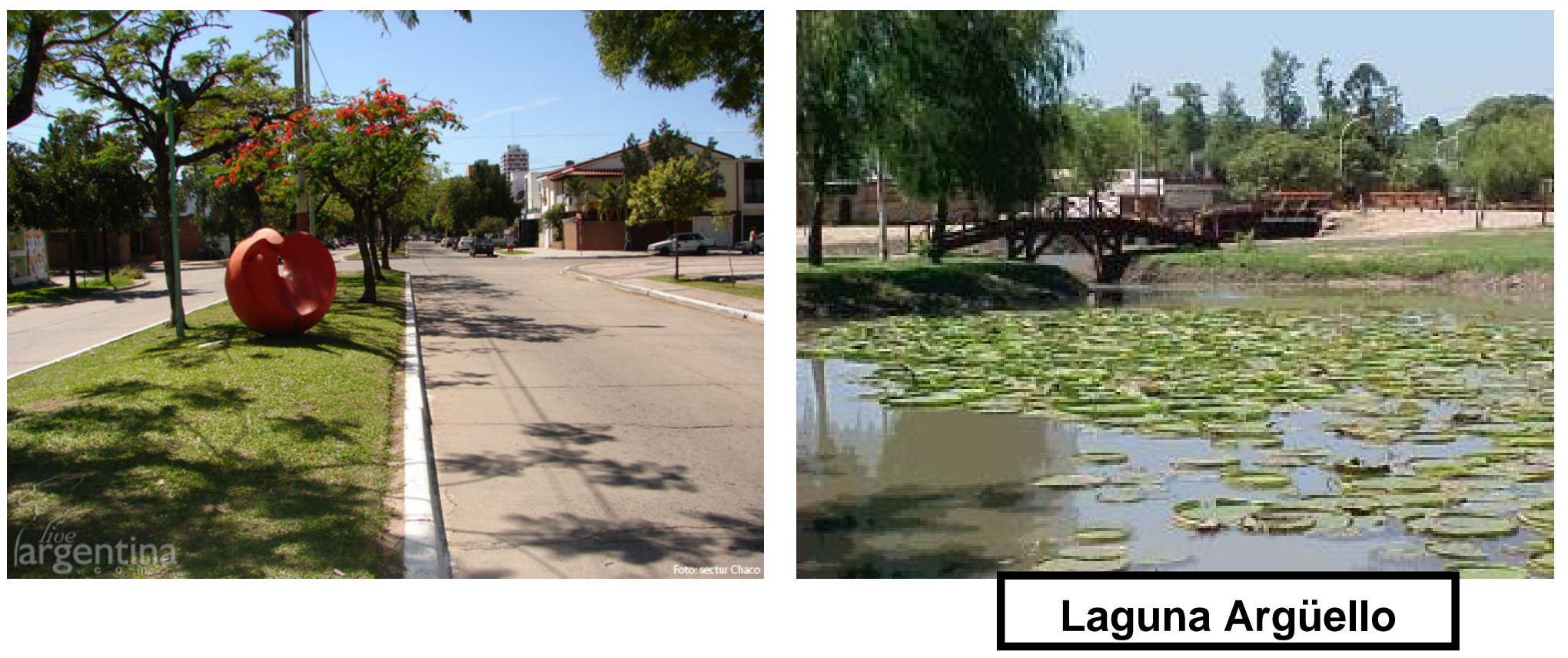


\section{ESPACIO CONSTRUIDO-VIENTOS}

Las edificaciones constituyen un obstáculo en la dirección de los vientos, disminuyen su velocidad y en consecuencia aumenta la frecuencia de calmas pero, también, se puede registrar un aumento de la turbulencia.

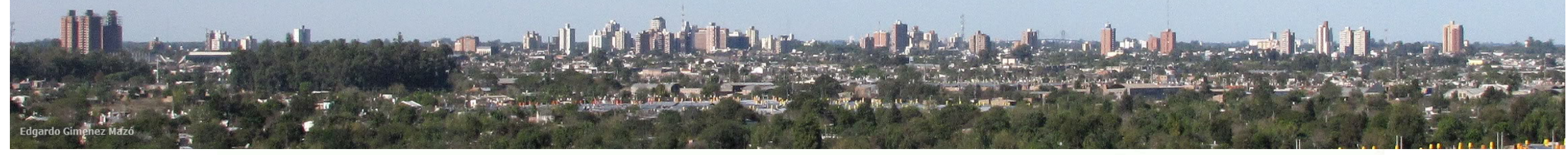

URBANA

SUBURBANA

RURAL

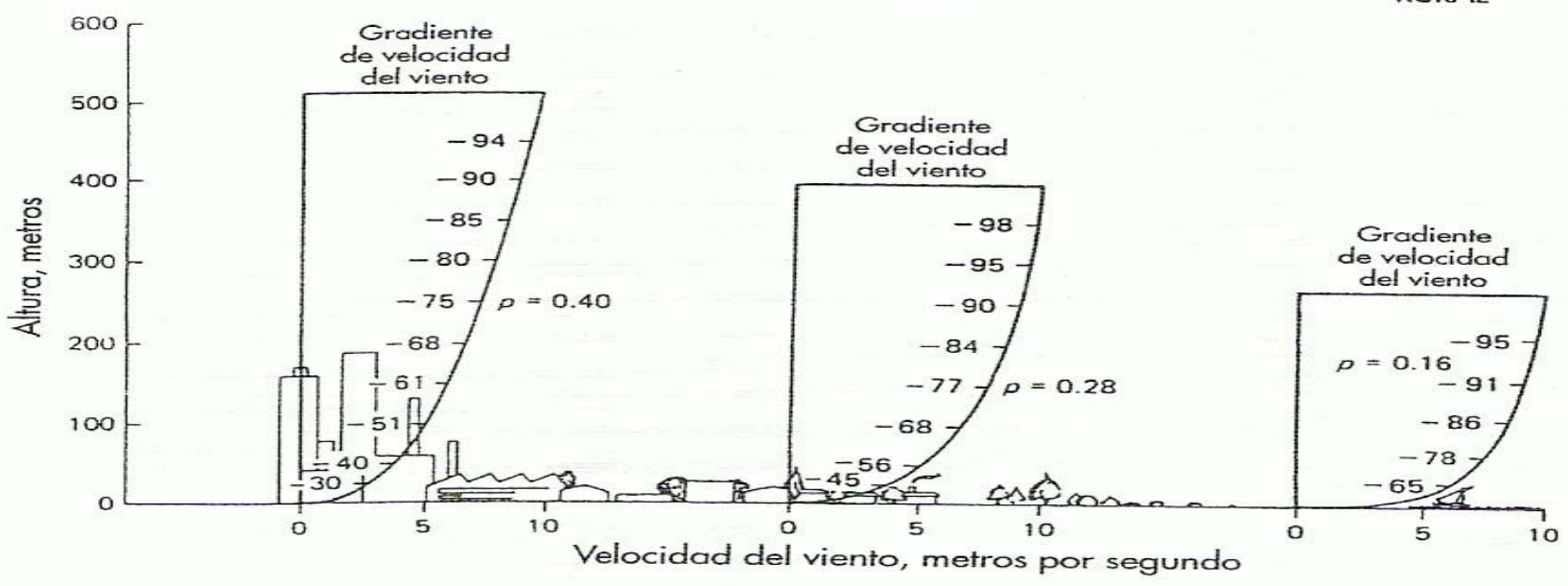

Publicado en formato digital: Prof. Claudia Verónica GÓMEZ y Prof. María Emilia PÉREZ. CLIMA Y URBANIZACIÓN. Resúmenes. Revista Geográfica Digital. IGUNNE. Facultad de 
Revista Geográfica Digital. IGUNNE. Facultad de Humanidades. UNNE. Año 9. № 18. Julio - Diciembre 2012. ISSN 1668-5180 Resistencia, Chaco

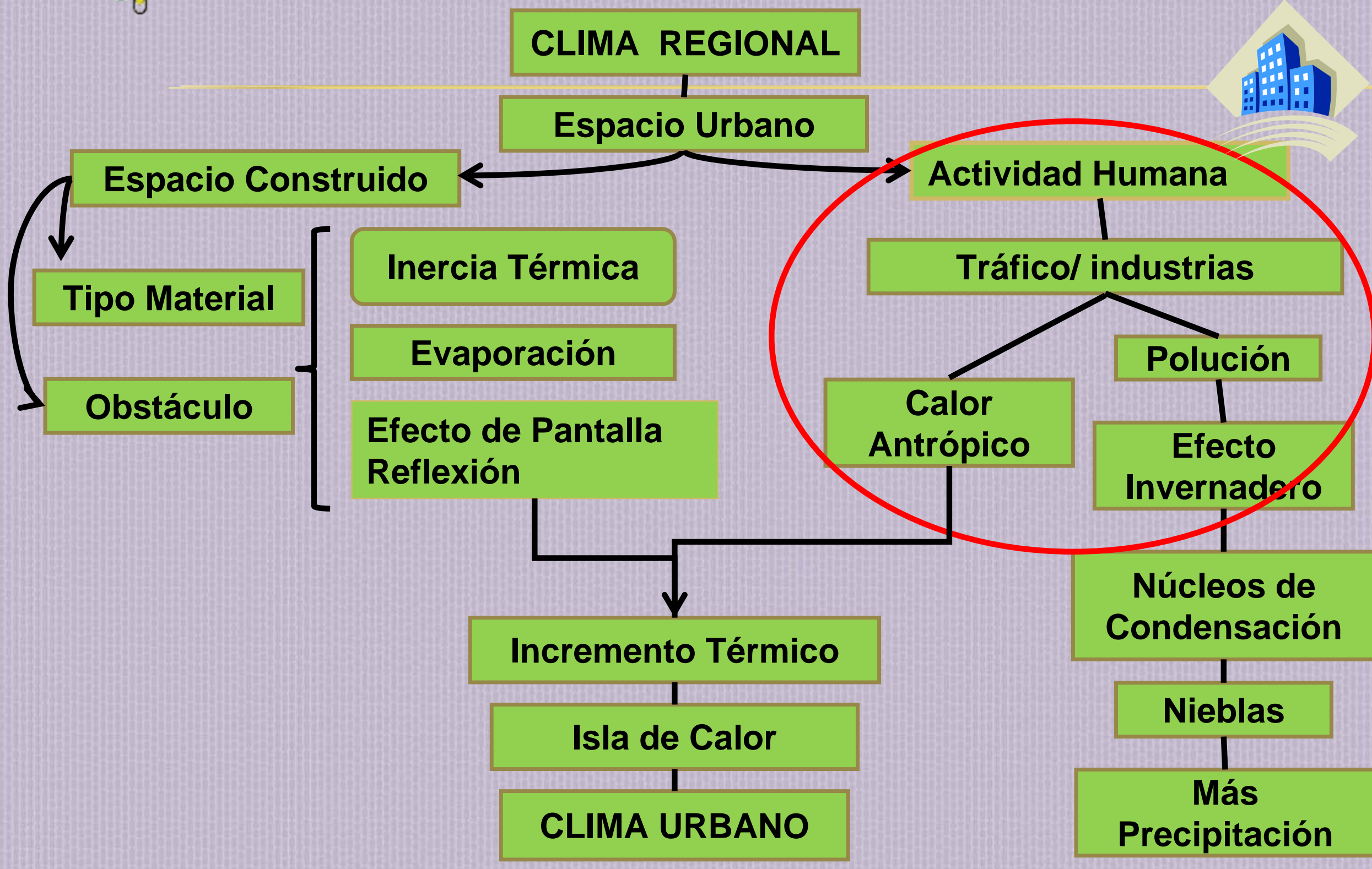


Revista Geográfica Digital. IGUNNE. Facultad de Humanidades. UNNE. Año 9. № 18. Julio - Diciembre 2012. ISSN 1668-5180 Resistencia,
Chaco

\section{ACTIVIDADES HUMANAS}

La polución (gases, humo, polen, polvo, aerosoles, etc.) del área urbana es producto de las distintas actividades que realiza la población y genera:

\section{Disminución de la radiación directa,}

Absorción de la radiación terrestre,

Aumento de la frecuencia de nieblas,

Disminución de la visibilidad,

Aumento de los núcleos de condensación.
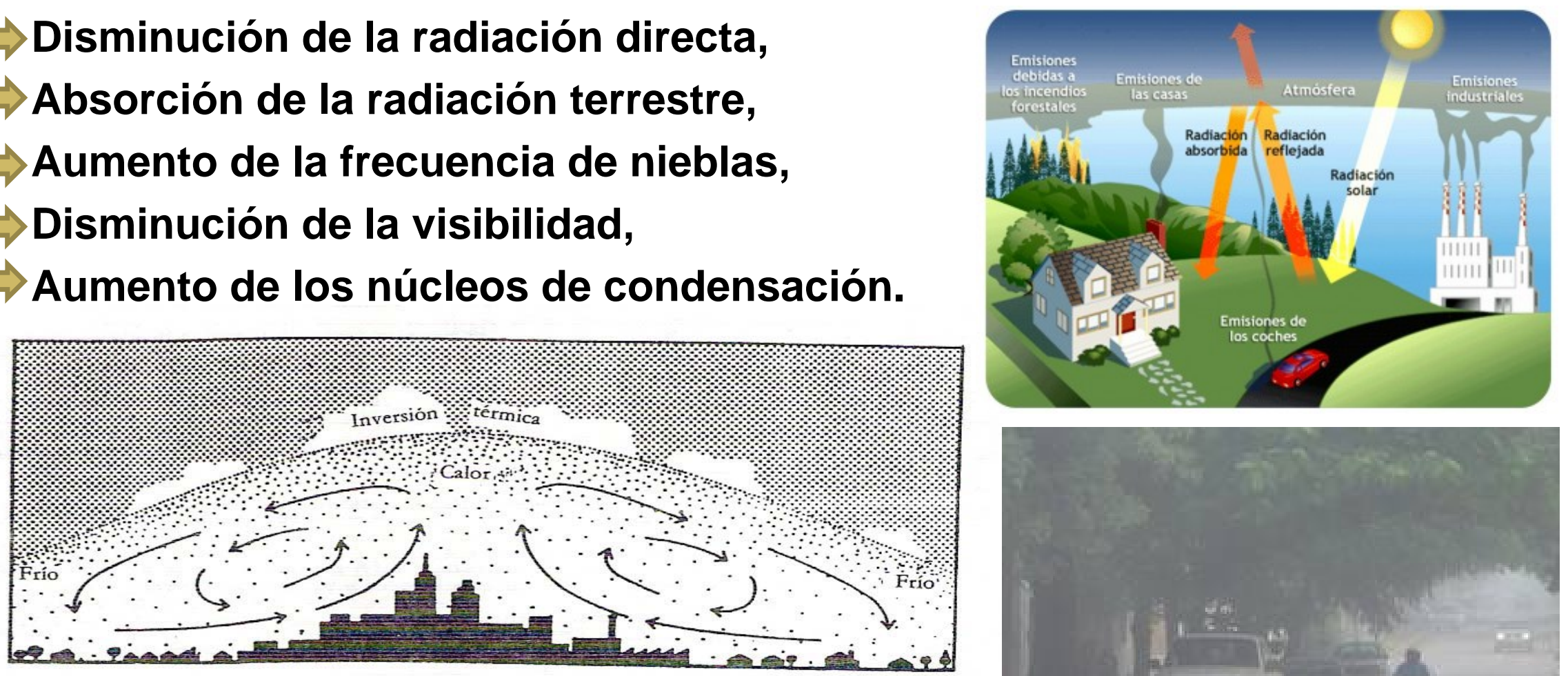

FIGURA 9.34. Sistema de brisas en la atmósfera urbana generada por la isla de calor cuando los vientos re gionales son débiles, con la formación de la característica cúpula de polvo o «boina» por debajo del nivel de inversión (según Zárate, 1994) 
1 Revista Geográfica Digital. IGUNNE. Facultad de Humanidades. UNNE. Año 9. No 18. Julio - Diciembre 2012. ISSN 1668-5180 Resistencia,

\section{ACTIVIDADES HUMANAS-ILUMINACIÓN}
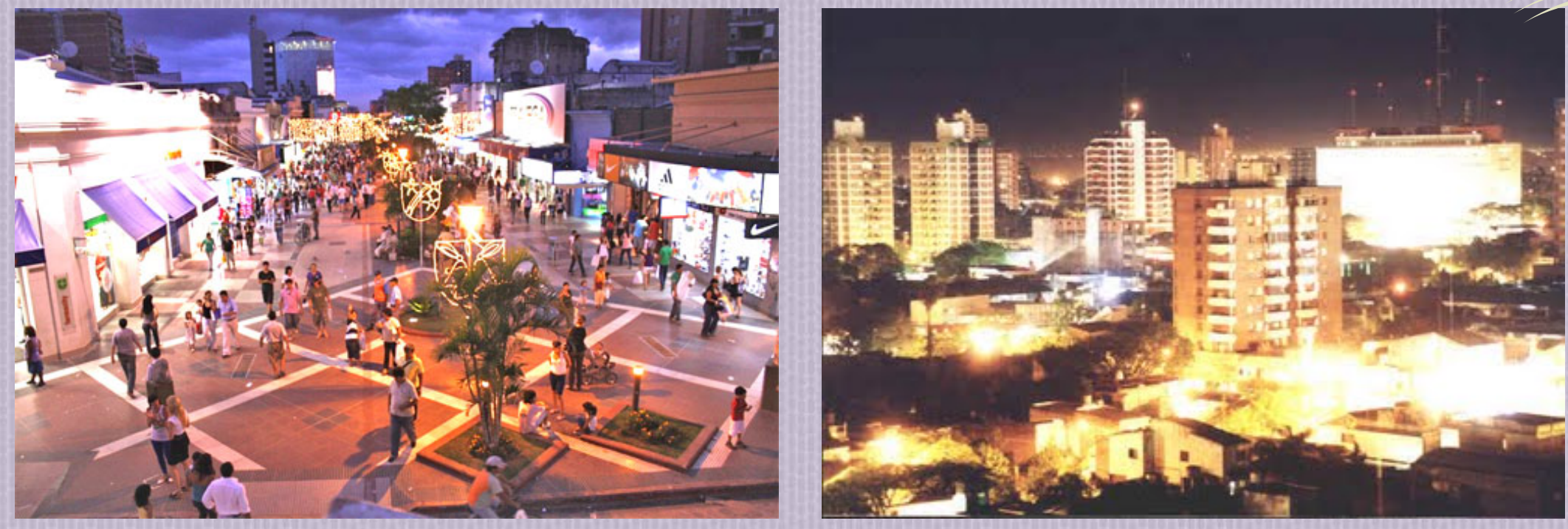

La iluminación artificial contribuye a mantener durante más tiempo valores altos de temperatura en lugares muy puntuales (microclima). 
- Revista Geográfica Digital. IGUNNE. Facultad de Humanidades. UNNE. Año 9. № 18. Julio - Diciembre 2012. ISSN 1668-5180 Resistencia, Chaco

\section{CLIMA URBANO: ISLA DE CALOR}
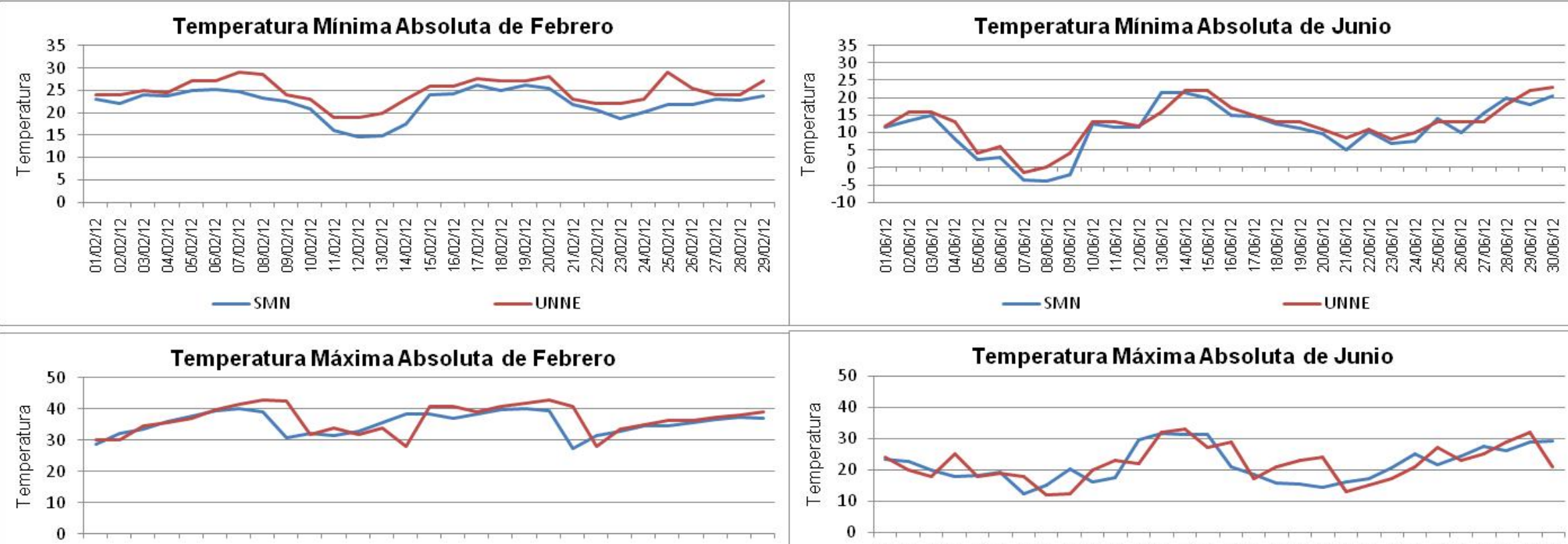

"

$\longrightarrow$ SMN

UUNNE

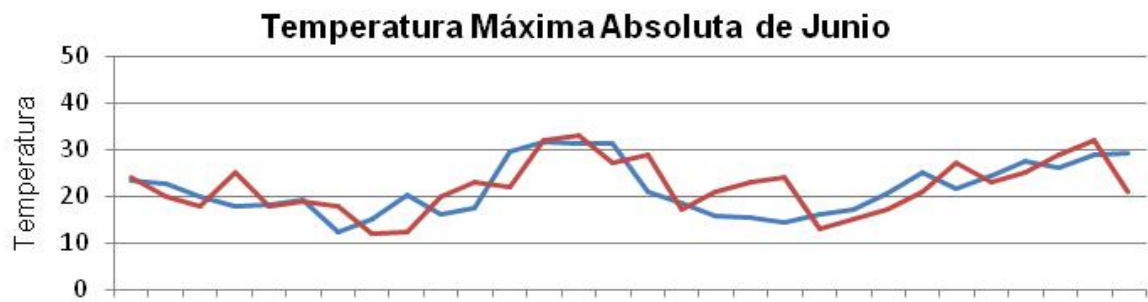

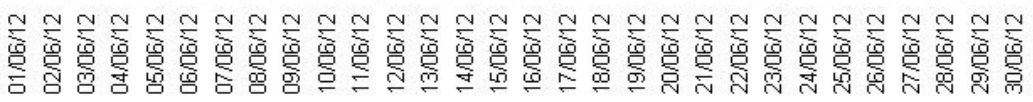

SMN

—UNNE

Los gráficos se han confeccionado con datos de temperaturas absolutas diarias de los meses de Febrero y Junio de 2012, extraídos de la página web del Servicio Meteorológico Nacional: http://www.smn.gov.ar/ y de la Estación Meteorológica de Capacitación de la Facultad de Ingeniería -UNNE- a cargo de Ruberto, Alejandro y Depettris, Carlos. 


\section{CLIMA URBANO: ISLA DE CALOR}

Isla de Calor:

- Se denomina de esta manera porque la variable más afectada es la temperatura,

* la intensidad de este fenómeno depende del tamaño de la ciudad (espacio construido),

- presenta una variación diaria y estacional. En la ciudad de Resistencia se ha analizado su comportamiento estacional y se puede decir que este evento se acentúa durante los meses de verano,

- Ia Isla de Calor es mayor en días despejados y con aire en calma. 


\section{CONFORTABILIDAD HUMANA}

"Son aquellas condiciones en que la mente expresa satisfacción del ambiente térmico (Ashrae)"

“Es la ausencia de irritación o malestar térmico (Givoni)”

Buscamos emplazamientos favorables
Conservamos los espacios verdes
Diseñamos casas /edificios de acuerdo a las características del medio 


\section{Agradecimientos:}

Al Profesor Alberto, Juan A. por facilitarnos fotografías aéreas de la ciudad de Resistencia.

A los Señores Ruberto A. y Depettris, C. por suministrarnos datos de temperaturas absolutas diarias medidos en la Estación Meteorológica de Capacitación-Facultad de IngenieríaUNNE.

\section{Bibliografía:}

-BARRY, R. y CHORLEY, R. (1972). "Atmósfera, Tiempo y Clima”. Barcelona, Omega.

-CUADRAT, J. y PITA, M. (2000). “Climatología”. Madrid. Cátedra, 2da Edición.-

-FERNANDEZ GARCIA, Felipe (1996). "Manual de Climatología Aplicada. Clima, Medio Ambiente y Planificación". Madrid. Síntesis S.A.

-FERNANDEZ GARCIA, Felipe (1994). "Clima y confortabilidad humana. Aspectos metodológicos". En: Serie Geográfica No 4 "El cambio climático y las actividades humanas". Madrid. Universidad de Alcalá.

\section{Páginas web:}

\section{www.smn.gov.arl}

http://www.diarionorte.com/

http://www.diariochaco.com/

http://www.argentour.com/ 